\title{
The role of laparoscopy in the propaedeutics of gynecological diagnosis ${ }^{1}$
}

Gislaine Laperuta Serafim Argentino', Flávia Neves Bueloni-Dias", Nilton José Leite', Gustavo Filipov Peres', Leonardo Vieira Elias', Vitória Cristina Bortolani"', Carlos Roberto Padovani'v, Daniel SpadotoDias" (i), Rogério Dias ${ }^{\mathrm{V}}$

'Assistant Physician, Gynecological Endoscopy and Family Planning Sector, Department of Gynecology and Obstetrics, Botucatu Medical School, Universidade Estadual Paulista (UNESP), Botucatu-SP, Brazil. Conception and design of the study; acquisition, analysis and interpretation of data; technical procedures; manuscript preparation.

"Clinical Assistant Professor, Department of Gynecology and Obstetrics, Botucatu Medical School, UNESP, Botucatu-SP, Brazil. Acquisition, analysis and interpretation of data; technical procedures; manuscript preparation.

'"Resident, Department of Gynecology and Obstetrics, Botucatu Medical School, UNESP, Botucatu-SP, Brazil. Acquisition of data,

IVFull Professor, Department of Biostatistics, Botucatu Biosciences Institute, UNESP, Botucatu-SP, Brazil. Statistics analysis. ${ }^{\vee}$ Associate Professor III, Department of Gynecology and Obstetrics, Botucatu Medical School, UNESP, Botucatu-SP, Brazil. Conception and design of the study, manuscript preparation.

\section{Abstract}

Purpose: To evaluate agreement between pre- and post-laparoscopy gynecological diagnosis in order to demonstrate the rationality of this minimally invasive technique use in gynecological propaedeutics.

Methods: Retrospective chart review study conducted between March 2010 and October 2016 based on a convenience sample. 315 patients undergoing surgical laparoscopy at the Center of Gynecologic Endoscopy and Family Planning of Botucatu Medical School/ UNESP. Pre- and postoperative diagnoses were compared by the diagnosis agreement test considering the proportions of events.

Results: Laparoscopy contributed to diagnosis in $59.6 \%$ of infertility cases ( $P>0.05)$, in $93.7 \%$ of chronic pelvic pain of undetermined origin $(P<0.01)$ and conclusively elucidated the diagnosis of acute abdomen and the ruling out of tubo-ovarian abcess $(P<0.05)$. Laparoscopy also increased the diagnosis of pelvic-abdominal adhesions in $76.7 \%(P>0.05)$.

Conclusion: The use of laparoscopy considerably contributed to diagnostic elucidation, especially in cases of undetermined chronic pelvic pain.

Key words: Laparoscopy. Endometriosis. Infertility, Female. Pelvic Pain. Techniques. Education, Medical. 


\section{Introduction}

Diagnosis plays a crucial role in clinical practice. It is the basis for developing an adequate treatment plan and establishing effective patient management strategies ${ }^{1}$. Accurate diagnosis reduces the risk of unnecessary therapies and optimizes the use of resources, particularly when they are limited, bringing benefits throughout the medical assistance process ${ }^{1,2}$. In the field of Gynecology, a careful diagnosis is especially critical because a great part of the symptoms and diseases that affect women may directly correlate with other specialties. Thus, misdiagnosis can shortly lead to the worsening of a patient's condition, aggravating morbidity and causing higher costs to the healthcare system $^{3,4}$.

Over the past years, laparoscopy has become a powerful propedeutic as well as therapeutic tool of modern gynecological practice. It can reduce the number of innappropiate procedures and unnecessary treatments with very low complication rates $^{5-9}$. In conjunction with other propedeutic procedures, laparoscopy may change the diagnostic conclusion in many gynecological cases with increased efficiency in the diagnosis of conditions undetected during previous clinical and ultrasound examinations s-9,9-12. $^{5}$.

Nonetheless, in many countries, medical residency programs in gynecology do not include laparoscopic training, be it for surgical therapeutic or even purely diagnostic procedures. Therefore, this study aimed to assess patients underwent laparoscopy to evaluate the consistency of agreement between pre- and post-laparoscopy gynecological diagnosis in order to demonstrate the rationality of laparoscopy use in gynecological propaedeutics, and thus expand the discussion about the basis of the training of future gynecologists.

\section{Methods}

Study design and sample selection

This retrospective chart review study was conducted to evaluale all patients undergoing surgical laparoscopy at the Center of Gynecologic Endoscopy and Family Planning of Botucatu Medical School/UNESP, Brazil between March 2010 and October 2016 (Fig. 1). Pre- and postoperative data were retrieved from the electronic database of the Botucatu Medical School Hospital/UNESP. The study was approved by the institution's Committee of Research Ethics and was exempted from the requirement for informed consent as it involved deidentified data acquired during routine care, and did not involve any biological material or contact with the patients. 


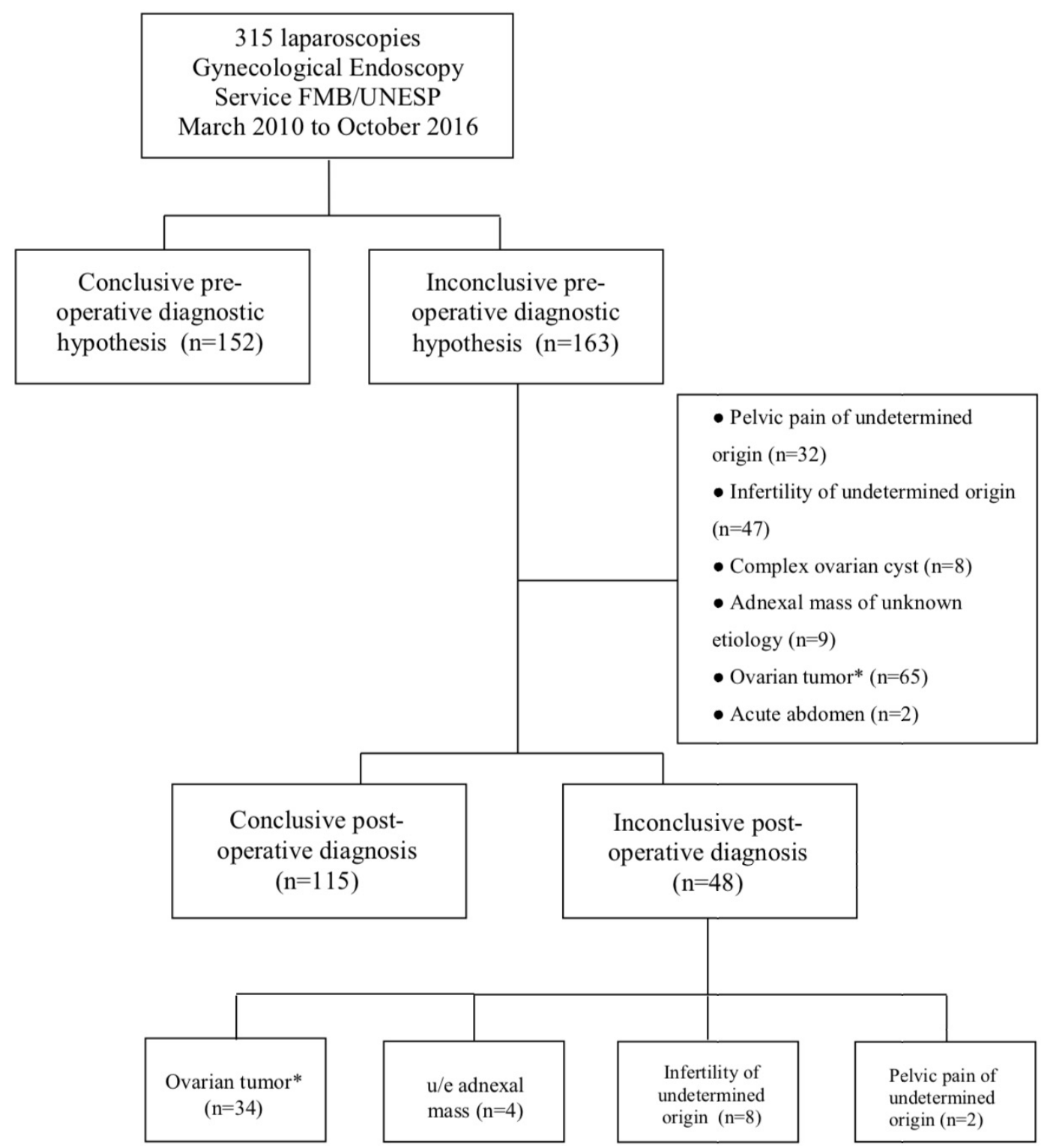

*benign, suspicious and malignant lesion

$\mathrm{u} / \mathrm{e}$ (unknown etiology)

Figure 1 - Flowchart of diagnosis in 315 patients who underwent surgical laparoscopy between March 2010 and October 2016 in the Gynecologic Endoscopy Service of Botucatu Medical School/UNESP.

\section{Data collection}

Data, such as age, body mass index $\left(\mathrm{BMl}=\mathrm{kg} / \mathrm{m}^{2}\right)$, parity, abortion, age at menarche, date of last menstruation, menstrual pattern, use of hormone therapy, history of pelvic inflammatory disease (PID), presence of systemic arterial hypertension (SAH), diabetes mellitus, thiroid diseases, dyslipidemia and smoking were transcribed 
into an Excel spreadsheet for analysis. Information on patients' clinical complaints, transvaginal-pelvic ultrasound findings, anatomopathological findings, type of surgical procedures performed, and the rate of complications observed before, during and after laparoscopy were also comparatively assessed.

\section{Statistical analysis}

Descriptive statistical analysis was performed. The absolute and relative frequencies of the study parameters were assessed. Mean, standard deviation, and minimum-maximum values of quantitative variables, as well as the absolute frequency and percentage of qualitative variables were estimated. Pre- and postoperative diagnoses were compared by the diagnosis agreement test considering the proportions of events ${ }^{13}$.

\section{Results}

Patient mean age was 35 years. The majority of women were overweight (BMI= $26.94 \pm 5.52$ ) and in reproductive age (84.1\%) (Table 1). Hormone contraceptives were used by $34.6 \%$, and history of treatment for uterine infection was reported by $11.4 \%$ of the patients. The most frequently reported complaint was chronic pelvic pain (34\%), followed by dysmenorrhea (15.9\%), desire for definitive contraception (15.6\%), and desire for reproduction (13\%) (Table 2). Eleven per cent of the women complained of significantly increased menstrual flow, while $14.3 \%$ had no clinical complaint and were referred to surgery due to incidental image findings, notably regarding adnexal formations. Nineteen per cent of the patients reported more than one clinical complaint of relevance.

Table 1 - Clinical and epidemiological characteristics of 315 patients who underwent surgical laparoscopy between March 2010 and October 2016 in the Gynecologic Endoscopy Service of Botucatu Medical School/UNESP.

\begin{tabular}{lc}
\hline Age & $35(13 ; 72)$ \\
BMI & $26.94( \pm 5.52)$ \\
Gestation & $2(0 ; 11)$ \\
Parity & $1(0 ; 8)$ \\
Abortion & $0(0 ; 3)$ \\
C-section & $0(0 ; 4)$ \\
Menacme & $265(84.1)$ \\
Menopause & $50(15.9)$ \\
Hormone contraceptive & $109(34.6)$ \\
PID history & $36(11.4)$ \\
SAH & $53(16.8)$ \\
Diabetes & $13(4.1)$ \\
Thireoidpathy & $18(5.7)$ \\
Dislipidemia & $12(3.8)$ \\
Smoking & $39(12.4)$ \\
\hline Median (minimum and maximum); Mean values $( \pm$ standard \\
deviation) \\
Frequency Distribution in absolute numbers and percentages n(\%) \\
BMI= Body mass index; PID= Pelvic inflammatory disease; \\
SAH= systemic arterial hypertension.
\end{tabular}

Table 2 - Clinical characteristics of 315 patients who underwent surgical laparoscopy between March 2010 and October 2016 in the Gynecologic Endoscopy Service of Botucatu Medical School/UNESP

\begin{tabular}{lc}
\hline Chronic pelvic pain & $107(34)$ \\
Dysmenorrhea & $50(15.9)$ \\
Desire for definitive contraception & $49(15.6)$ \\
Asymptomatic & $45(14.3)$ \\
Reproduction desire & $41(13)$ \\
Increased menstrual flow & $36(11.4)$ \\
Acute pelvic pain & $15(4.8)$ \\
Dyspareunia & $14(4.4)$ \\
Irregular menstrual cycle & $8(2.5)$ \\
Dyschezia & $5(1.6)$ \\
Postmenopausal bleeding & $4(1.3)$ \\
Dysuria & $1(0.3)$ \\
\hline Frequency distribution in absolute numbers and percentages \\
$\mathrm{n}(\%)$
\end{tabular}


Laparoscopy was inconclusive in $17 \%$ of the patients assessed due to infertility with no apparent cause. However, in $83 \%$ of these cases it was essential for establishing the diagnosis of polycystic ovary (2.1\%) with no other reason for infertility, ovarian endometrioma (6.4\%), adhesions (17\%), and endometriosis (57.5\%) ( $P>0.05) \quad$ (Fig. 2 ). The diagnosis of chronic pelvic pain of undetermined origin was postoperatively diagnosed as adnexal cyst (3.1\%), myoma (6.3\%), ovarian endometrioma (6.3\%), hydrosalpinge (15.6\%), adhesions (18.7\%), and endometriosis (43.7\%) (Fig. 3).

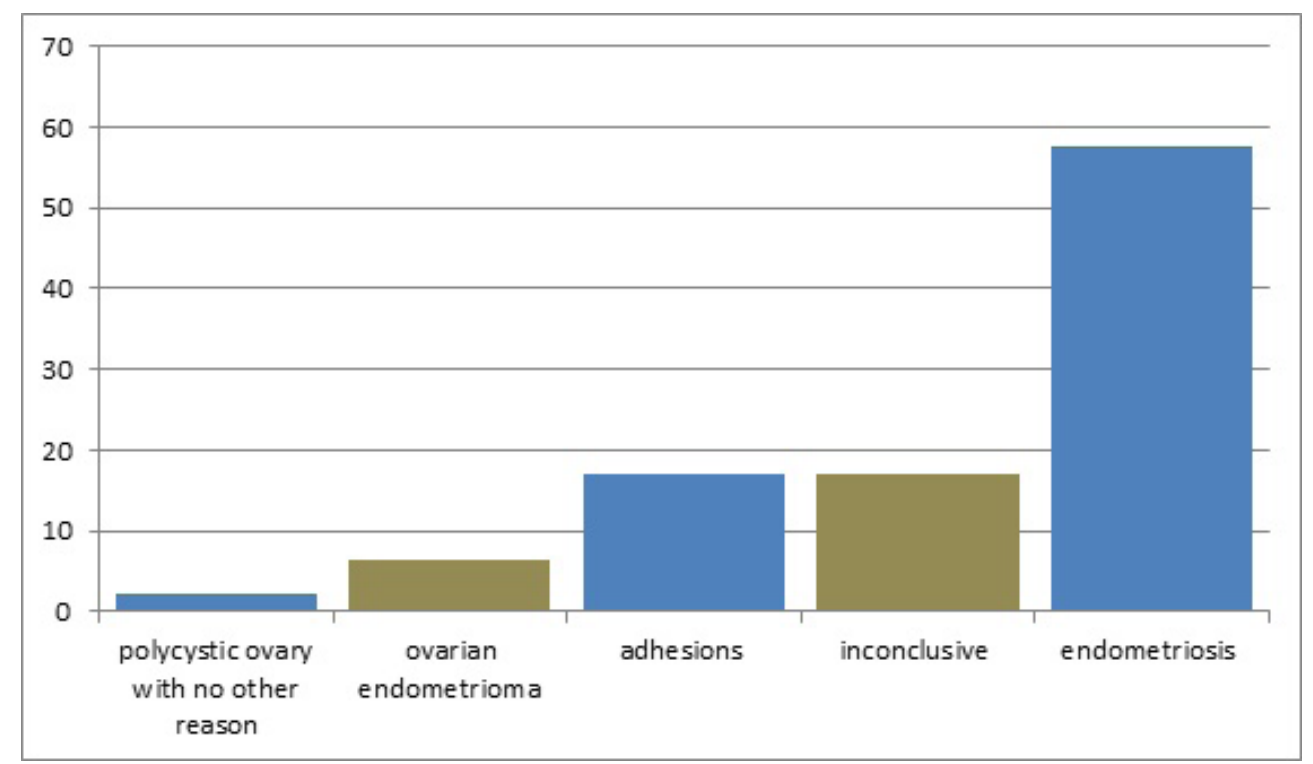

Figure 2 - Post-laparoscopy diagnosis of preoperative undefined infertility.

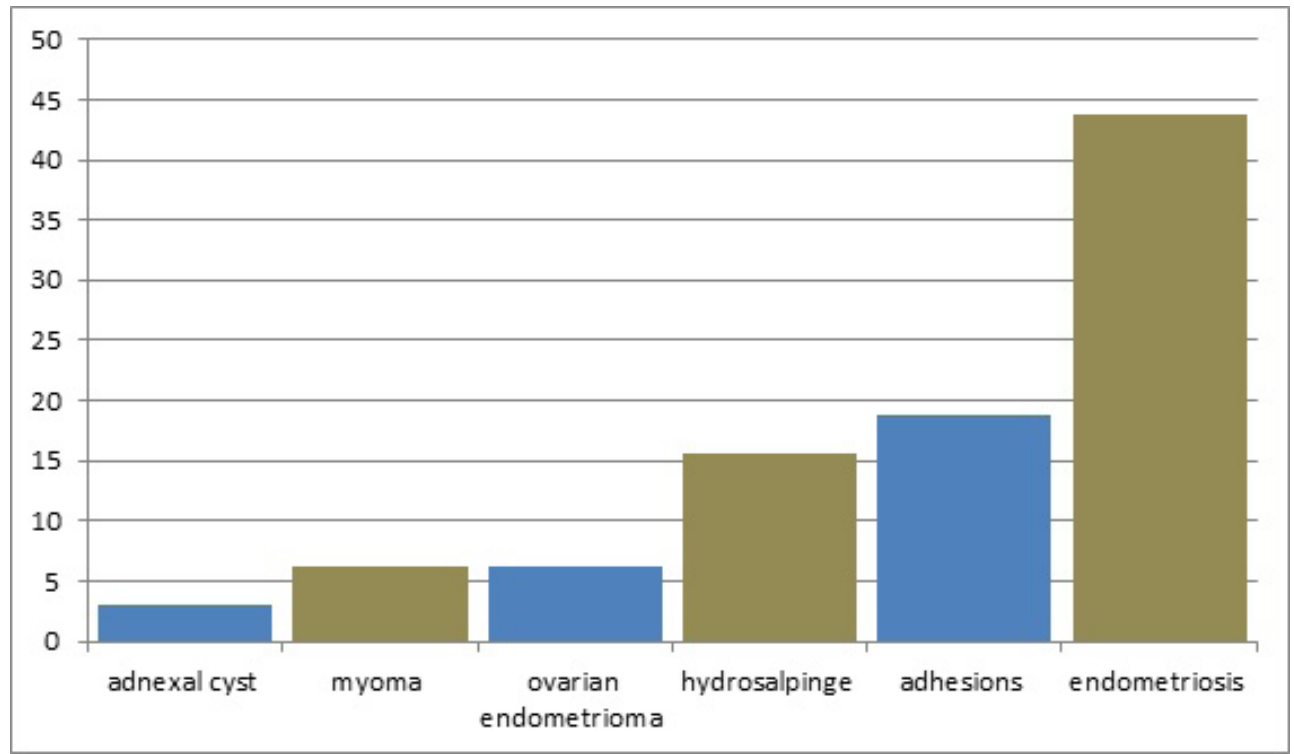

Figure 3 - Post- laparoscopy diagnosis of preoperative chronic pelvic pain of undetermined origin. 
The pre-laparoscopy diagnosis of complex ovarian cyst was related with the post-laparoscopy diagnosis of hemorrhagic corpus luteum (37.5\%), ovarian tumor (ovarian teratoma on anatomopathology) (50\%), and retention cyst (12.5\%). In $40 \%$ of the cases with a preoperative diagnosis of ovarian tumor, and in $77.8 \%$ of cases with a diagnosis of adnexal mass of unknown etiology, laparoscopy detected uterine myoma, endometriosis, adhesions and tubo-ovarian abcesses, but with no statistical differences (Table 3).

In general, laparoscopy contributed to diagnosis elucidation in $59.6 \%$ of infertility cases ( $P>0.05), 93.7 \%$ of chronic pelvic pain of undetermined origin $(P<0.01), 87.5 \%$ of complex ovarian cyst cases $(P<0.05), 40 \%$ of ovarian tumor cases ( $P>0.05)$, and $77.8 \%$ of adnexal mass of unknown etiology cases ( $p>0.05)$ (Table 3). Furthermore, in this study, laparoscopy changed the preoperative diagnosis of acute abdomen to tubo-ovarian abcess $(P<0.05)$, and ruled out the preoperative diagnostic hypothesis of tubo-ovarian abcess by revealing an ectopic pregnancy and apendicitis $(P<0.05)$. Laparoscopy also determined a $76.7 \%$ increase in the diagnosis of pelvic-abdominal adhesions $(P>0.05)$. The rate of complications in our study was low, with emphasis on bladder $(0.6 \%)$, ureter $(0.3 \%)$ and intestinal injuries (0.3\%).

Table 3 - Distribution of agreement between pre- and postoperative diagnoses.

\begin{tabular}{|c|c|c|c|c|}
\hline \multirow[t]{2}{*}{ PRE-diagnosis } & \multicolumn{2}{|c|}{ POST-diagnosis } & \multirow[t]{2}{*}{ Total } & \multirow[t]{2}{*}{$P$ value } \\
\hline & Agreement & Disagreement & & \\
\hline Infertility & $40.4 \%$ & $59.6 \%$ & 47 & $>0.05$ \\
\hline Pelvic pain & $6.3 \%$ & $93.7 \%$ & 32 & $<0.01$ \\
\hline Complex ovarian cyst & $12.5 \%$ & $87.5 \%$ & 8 & $<0.05$ \\
\hline Ovarian tumor & $60.0 \%$ & $40.0 \%$ & 65 & $>0.05$ \\
\hline u/e Adnexal mass & $22.2 \%$ & $77.8 \%$ & 9 & $>0.05$ \\
\hline Acute abdomen & $0.0 \%$ & $100.0 \%$ & 2 & $<0.05$ \\
\hline Tubo-ovarian abcess & $0.0 \%$ & $100.0 \%$ & 2 & $<0.05$ \\
\hline Adhesions & $23.3 \%$ & $76.7 \%$ & 7 & $>0.05$ \\
\hline
\end{tabular}

Diagnosis agreement test (pre-post) considering the proportions of events $\mathrm{P}<0.05$ statistical significance

u/e (unknown etiology)

\section{Discussion}

Compared to conventional open surgery, laparoscopy has numerous advantages, such as (1) less postoperative pain, (2) shorter hospital stay, (3) lower rates of postoperative complications, (4) early return to daily activities, and (5) better esthetic effect. These benefits combined decrease the direct and indirect costs related to the surgical procedure ${ }^{3,5,7,11}$. In cases where the etiology of the condition is not fully clear, laparoscopy has been shown to be a safe and reliable adjunct to gynecological diagnosis that may spare patients an exploratory laparotomy and its greater risks of complications ${ }^{14-19}$.

To some authors, laparoscopy should be an integral part of the evaluation of women with pelvic pain of undetermined origin due to its safety and reliability ${ }^{20}$. Others additionally state that laparoscopy allows for a much more accurate gynecological 
diagnosis as it may confirm or rule out clinical impressions, establish a diagnosis, follow and explore the course of the disease as well as change or complement treatment ${ }^{21,22}$. Several comparative studies have shown that the use of laparoscopy increased the rate of success in the diagnosis of different gynecological conditions $^{9,22,23}$. Despite the evidence reported in the literature, in many countries, medical residency programs aiming at providing basic introductory training in diagnostic laparoscopy do not integrate as part of the curriculum. In countries were those programs were implemented there is no standardized training adopted leading to a very heterogeneous formation of future professionals ${ }^{24-26}$.

Regulatory bodies have already emphasized the need of expanding validated training programs to prepare professionals for the increasing use of laparoscopy before progression to real procedures ${ }^{25}$. Nevertheless, difficulties in implementing a training program for residents in gynecology are encountered in many countries. The main obstacles reported are lack of planning and structure within institutions, cost constraints, shortage of skilled professionals available for teaching and guide residents and limited residents' working hours ${ }^{24,25,27-30}$.

It is estimated that $73 \%$ of programs lead off laparoscopic skills in North America but only $29 \%$ of residencies provide a structured surgical curriculum and only $55 \%$ of residency programs have facilities for training in laparoscopy in the United States ${ }^{26,31,32}$. Moreover, a recent study on accredited North American Obstetrics and Gynecology residency programs revealed that more than $40 \%$ were dissatisfied with their current laparoscopy training ${ }^{33}$. As a matter of fact, despite residency programs are trying to incorporate simulation into the resident training curriculum to supplement the handson experience gained in the operating room, this simulation laboratories continue to be under utilized by surgical trainees ${ }^{29}$. In most countries, including Latin America, there is not even teaching models for laparoscopic skills or validated tools for its evaluation during residency ${ }^{32}$.

In this study, after excluding the cases of adnexal and/or ovarian diseases (adnexal masses of unknown etiology, ovarian tumors and complex ovarian cysts) which require histopathological confirmation and cannot be accurately identified surgically, diagnostic elucidation after laparoscopy occurred in $93.7 \%$ of the cases of pelvic pain of unknown etiology $(P<0.01)$, and $59.6 \%$ of the cases of infertility with no apparent cause ( $p>0.05)$. Furthermore, laparoscopy was conclusive in the diagnosis of acute abdomen, even though there was a low number of cases with this condition in our series $(P<0.05)$.

The introduction of laparoscopy into clinical practice has opened up new avenues for the diagnosis and management of chronic pelvic pain. It is estimated that more than half of patients with a normal preoperative pelvic examination will present abnormal findings during the laparoscopic procedure ${ }^{11,34}$. The literature shows that in women with chronic pelvic pain undergoing laparoscopy, the diagnosis may remain inconclusive in approximately $35 \%$ of cases, and endometriosis and adhesions can be diagnosed in 33\% and $24 \%$, respectively ${ }^{10,11,34,35}$. These findings represent about $90 \%$ of all laparoscopies in women with pelvic pain suggesting that the predominant role of laparoscopy in the evaluation of these patients is to diagnose or rule out endometriosis and adhesions.

Except in cases of endometrioma, ovarian retention syndromeand ovarian residual syndrome, ovarian cysts are not a common cause of chronic pelvic pain. The laparoscopic assessment of patients with chronic pelvic pain reveals ovarian cysts in only $4 \%$ of all cases excluding endometriomas ${ }^{11}$. Endometriosis, 
in turn, is a common laparoscopic diagnosis in patients with chronic pelvic pain, found in $15 \%$ to $80 \%$ of women undergoing surgery for chronic pelvic pain ${ }^{12,36}$.

Similarly, endometriosis is estimated to affect up to $50 \%$ of infertile women, and its severity appears to correlate with reduced fertility ${ }^{37}$. Infertility is the classical indication for propedeutic/therapeutic laparoscopy, which is indispensable to elucidate cases with no apparent cause ${ }^{38-40}$. According to noncontrolled retrospective studies, diagnostic laparoscopy performed after several failed ovulation induction treatment cycles reveal significant pelvicpathologyamenable to surgical treatment ${ }^{40}$. Laparoscopy indicates intraabdominal abnormalities in 36\%-68\% of cases, even after normal hysterosalpingography ${ }^{38,39}$. Depending on the severity of laparoscopic findings, the initial treatment decision may be replaced by direct laparoscopic intervention, a laparotomic approach to fertility restoration or in vitro fertilization. This implies that, in addition to being a clinically important diagnostic tool, laparoscopy is essential for infertility treatment decision making ${ }^{39}$.

In this study, laparoscopy also proved to aid the diagnosis of tubo-ovarian abcess $(P<0.05)$. Despite the small number of cases, these findings corroborate the role of laparoscopy as a specific clinical criterion for the diagnosis of complicated pelvic inflammatory disease ${ }^{15,41}$. Although no statistical difference was reached, laparoscopy increased in $76.7 \%$ the diagnosis of pelvic-abdominal adhesions, demonstrating that preoperative propedeutics is still ineffective to establish the diagnosis of this condition. Adhesions are commmon etiologic factors for infertility, dyspareunia, intestinal obstruction and chronic pelvic pain albeit their role in the physiopathology of pain remains unclear $^{42}$. Laparoscopy in 1,061 patients revealed that pelvic adhesions (found in $32.5 \%$ of cases) is the most common cause of chronic pain ${ }^{34,43}$.
The use of laparoscopy can reveal treatable conditions, not detected using other methods, with a very low rate of complications. In our study, the rate of potentially severe complications ranged from $0.3 \%$ to $0.6 \%$. A survey of 6.451 laparoscopic procedures showed an overall complication rate of $0.65 \%$ $(42 / 6451)$. However, this rate rose to $0.80 \%$ (39/4865) when surgical laparoscopy was compared to merely diagnostic laparoscopy that was associated with a complication rate of $0.19 \%(3 / 1586)(P<0.001)^{44}$.

The benefits of this minimally invasive technique indicate that an in-depth discussion on reshaping medical residency programs is necessary as to adjust them to the new technology available as well as to today's reality. Given its propedeutic nature and association with very low complications risks, diagnostic laparoscopy should be routinely addressed in the training of future gynecologists. All efforts should be made so that health policies contemplate the dissemination and increasing use of laparoscopy, which has been demonstrated to offer numerous advantages throughout the medical assistance system, especially in the field of gynecology.

\section{Take home messages}

- Since it is not included in the training of resident doctors in most services worldwide, laparoscopy's potential for development in still considerable;

- The propedeutic role of laparoscopy for elucidating the diagnosis of several conditions of undetermined origin, notably complaints related to infertility and chronic pelvic pain, should not be disregarded;

- Programs of medical residency in gynecology including training in the use of propedeutic/diagnostic laparoscopy should be encouraged by medical care improvement policies. This can 
bring direct and indirect benefits, besides reducing costs throughout the healthcare system;

- Training in therapeutic laparoscopy should be provided in specialized centers because the learning curve, despite being reproducible, takes quite long and depends on the number of procedures performed by the surgeon.

\section{References}

1. Bachmann LM, ter Riet G, Clark TJ, Gupta JK, Khan KS. Probability analysis for diagnosis of endometrial hyperplasia and cancer in postmenopausal bleeding: an approach for a rational diagnostic workup. Acta Obstet Gynecol Scand. 2003;82(6):564-9. PMID: 12780428.

2. Reid MC, Lachs MS, Feinstein AR. Use of methodological standards in diagnostic test research. Getting better but still not good. JAMA. 1995;274(8):645-51. PMID: 7637146.

3. Tsaltas J, Magnus A, Mamers PM, Lawrence AS, Lolatgis N, Healy DL. Laparoscopic and abdominal hysterectomy: a cost comparison. Med J Aust. 1997;166(4):2057. PMID: 9066551.

4. Flasar $\mathrm{MH}$, Goldberg E. Acute abdominal pain. Med Clin North Am. 2006;90(3):481503. PMID: 16473101.

5. Ou CS, Rowbotham R. Laparoscopic diagnosis and treatment of nontraumatic acute abdominal pain in women. J Laparoendosc Adv Surg Tech A. 2000;10(1):41-5. PMID: 10706302.

6. Sozuer EM, Bedirli A, Ulusal M, Kayhan E, Yilmaz Z. Laparoscopy for diagnosis and treatment of acute abdominal pain. J Laparoendosc Adv Surg Tech A. 2000;10(4):203-7. PMID: 10997843.

7. Kondo W, Rangel M, Tirapelle R, Garcia MJ, von Bahten LC, Laux GL, Smaniotto B. Emprego da laparoscopia em mulheres com dor abdominal aguda. Rev Bras Videocir. 2006 Mar;4(1):3-8.

8. Tan BP, Ong CL. Ultrasonographical diagnosis of acute gynaecological pain. Singapore Med J. 2008;49(6):511-5; quiz 6. PMID: 18581029.

9. Hsu AL, Sinaii N, Segars J, Nieman LK,
Stratton P. Relating pelvic pain location to surgical findings of endometriosis. Obstet Gynecol. 2011;118(2 Pt 1):223-30. PMID: 21775836.

10. Howard FM. The role of laparoscopy in the evaluation of chronic pelvic pain: pitfalls with a negative laparoscopy. J Am Assoc Gynecol Laparosc. 1996;4(1):85-94. PMID: 9050719.

11. Howard FM. The role of laparoscopy as a diagnostic tool in chronic pelvic pain. Baillieres Best Pract Res Clin Obstet Gynaecol. 2000;14(3):467-94. PMID: 10962637.

12.Lamvu G, Tu F, As-Sanie S, Zolnoun D, Steege JF. The role of laparoscopy in the diagnosis and treatment of conditions associated with chronic pelvic pain. Obstet Gynecol Clin North Am. 2004;31(3):619-30. PMID: 15450323.

13. Norman GR, Streiner DL. Biostatistics: the bare essentials. 3ed. Shelton, Conn.: People's Medical Pub. House; 2008.

14. Mereu L, Ruffo $G$, Landi $S$, Barbieri $F$, Zaccoletti R, Fiaccavento A, Stepniewska A, Pontrelli G, Minelli L. Laparoscopic treatment of deep endometriosis with segmental colorectal resection: short-term morbidity. J Minim Invasive Gynecol. 2007;14(4):463-9. PMID: 17630164.

15.Schorge JO, Williams JW. Williams gynecology. New York: McGraw-Hill Medical; 2008.

16.Shrestha J, Saha R. Comparison of laparoscopy and laparotomy in the surgical management of ectopic pregnancy. J Coll Physicians Surg Pak. 2012;22(12):760-4. PMID: 23217480.

17. Coolen $A L$, van Oudheusden $A M$, van Eijndhoven $\mathrm{HW}$, van der Heijden TP, Stokmans RA, Mol BW, Bongers MY. A Comparison of complications between open abdominal sacrocolpopexy and laparoscopic sacrocolpopexy for the treatment of vault prolapse. Obstet Gynecol Int. 2013;2013:528636. PMID: 24191158.

18.Liu M, Li L, He Y, Peng D, Wang X, Chen W, Fu X, Ma Y. Comparison of laparoscopy and laparotomy in the surgical management of early-stage ovarian cancer. Int J Gynecol Cancer. 2014;24(2):352-7. PMID: 24407575. 19.Terai Y, Tanaka T, Sasaki H, Kawaguchi H, Fujiwara S, Yoo S, Tanaka Y, Tsunetoh S, Kanemura M, Ohmichi M. Total laparoscopic 
modified radical hysterectomy with lymphadenectomy for endometrial cancer compared with laparotomy. J Obstet Gynaecol Res. 2014;40(2):570-5. PMID: 24118459.

20.Newham AP, van der Spuy ZM, Nugent F. Laparoscopic findings in women with chronic pelvic pain. S Afr Med J. 1996;86(9 Suppl):1200-3. PMID: 9180785.

21.Sharma D, Dahiya K, Duhan N, Bansal R. Diagnostic laparoscopy in chronic pelvic pain. Arch Gynecol Obstet. 2011;283(2):2957. PMID: 20072784.

22. Baloch S, Khaskheli MN, Malik AM. Diagnostic laparoscopic findings in chronic pelvic pain. J Coll Physicians Surg Pak. 2013;23(3):190-3. PMID: 23458041.

23.Janssen EB, Rijkers AC, Hoppenbrouwers K, Meuleman C, D'Hooghe TM. Prevalence of endometriosis diagnosed by laparoscopy in adolescents with dysmenorrhea or chronic pelvic pain: a systematic review. Hum Reprod Update. 2013;19(5):570-82. PMID: 23727940.

24.Patel NR, Makai GE, Sloan NL, Della Badia CR. Traditional versus simulation resident surgical laparoscopic salpingectomy training: a randomized controlled trial. J Minim Invasive Gynecol. 2016;23(3):372-7. PMID: 26590067.

25. Shore EM, Grantcharov TP, Husslein $H$, Shirreff L, Dedy NJ, McDermott CD, Lefebvre GG. Validating a standardized laparoscopy curriculum for gynecology residents: a randomized controlled trial. Am J Obstet Gynecol. 2016;215(2):204 e1- e11. PMID: 27131588.

26. Moawad GN, Tyan P, Kumar D, KrapfJ, Marfori C, Abi Khalil ED, Robinson J. Determining the effect of external stressors on laparoscopic skills and performance between obstetrics and gynecology residents. J Surg Educ. 2017;74(5):862-6. PMID: 28552418.

27.Nagendran M, Gurusamy KS, Aggarwal R, Loizidou M, Davidson BR. Virtual reality training for surgical trainees in laparoscopic surgery. Cochrane Database Syst Rev. 2013 (8):CD006575. PMID: 19160288.

28.Dehabadi $M$, Fernando $B$, Berlingieri $P$. The use of simulation in the acquisition of laparoscopic suturing skills. Int J Surg. 2014;12(4):258-68. PMID: 24503123.

29.Shetty S, Zevin B, Grantcharov TP, Roberts KE,
Duffy AJ. Perceptions, training experiences, and preferences of surgical residents toward laparoscopic simulation training: a resident survey. J Surg Educ. 2014;71(5):727-33. PMID: 24794063.

30.Enani G, Watanabe $Y$, McKendy KM, Bilgic E, Feldman LS, Fried GM, Vassiliou MC. What are the training gaps for acquiring laparoscopic suturing skills? J Surg Educ. 2017;74(4):656-62. PMID: 28385488.

31. Kirby TO, Numnum TM, Kilgore LC, Straughn JM. A prospective evaluation of a simulatorbased laparoscopic training program for gynecology residents. J Am Coll Surg. 2008;206(2):343-8. PMID: 18222390.

32. Fernandes CF, Ruano JM, Kati LM, Noguti AS, Girao MJ, Sartori MG. Assessment of laparoscopic skills of Gynecology and Obstetrics residents after a training program. Einstein (Sao Paulo). 2016;14(4):468-72. doi: 10.1590/s1679-45082016ao3752.

33.Shore EM, Lefebvre GG, Grantcharov TP. Gynecology resident laparoscopy training: present and future. Am J Obstet Gynecol. 2015;212(3):298-301, 298 e1. PMID: 25068561.

34.Chhetri S. Laparoscopy as a diagnostic tool in the evaluation of chronic pelvic pain in women. World J Laparosc Surg. 2009;2(2):302. doi: 10.3126/jnhrc.v7i1.2279.

35.Cox L, Ayers S, Nala K, Penny J. Chronic pelvic pain and quality of life after laparoscopy. Eur J Obstet Gynecol Reprod Biol. 2007;132(2):214-9. PMID: 16730874.

36. Howard FM. The role of laparoscopy in chronic pelvic pain: promise and pitfalls. Obstet Gynecol Surv. 1993;48(6):357-87. PMID: 8327235.

37.Cranney R, Condous G, Reid S. An update on the diagnosis, surgical management, and fertility outcomes for women with endometrioma. Acta Obstet Gynecol Scand. 2017;96(6):633-43. PMID: 28186620.

38. Fatum M, Laufer N, Simon A. Investigation of the infertile couple: should diagnostic laparoscopy be performed after normal hysterosalpingography in treating infertility suspected to be of unknown origin? Hum Reprod. 2002;17(1):1-3. PMID: 11756351.

39. Tanahatoe S, Hompes PG, Lambalk CB. Accuracy of diagnostic laparoscopy in the infertility work-up before intrauterine insemination. Fertil Steril. 2003;79(2):361- 
6. PMID: 12568846.

40.Bosteels J, Van Herendael B, Weyers S, D'Hooghe T. The position of diagnostic laparoscopy in current fertility practice. Hum Reprod Update. 2007;13(5):477-85. PMID: 17562734.

41.Kreisel K, Torrone E, Bernstein K, Hong J, Gorwitz R. Prevalence of Pelvic inflammatory disease in sexually experienced women of reproductive age - United States, 20132014. MMWR Morb Mortal Wkly Rep. 2017;66(3):80-3. doi: 10.15585/mmwr. mm6603a3.

42.Karnath BM, Breitkopf DM. Acute and chronic pelvic pain in women. Hospital Physician. 2007:41-8.

43.Drozgyik I, Vizer M, Szabo I. Significance of laparoscopy in the management of chronic pelvic pain. Eur J Obstet Gynecol Reprod
Biol. 2007;133(2):223-6. PMID: 16854515. 44.Wang PH, Lee WL, Yuan CC, Chao HT, Liu WM, Yu KJ, Tsai WY, Wang KC. Major complications of operative and diagnostic laparoscopy for gynecologic disease. J Am Assoc Gynecol Laparosc. 2001;8(1):68-73. PMID: 11172117.

\section{- Acknowledgements}

Special thanks to Professors Eliana Aguiar Petri Nahás e Jorge Nahás Neto for their academic-scientific support, to Mariza Branco da Silva for manuscript English revision, and Rosemary Cristina da Silva for reviewing bibliography.

\section{Correspondence:}

Daniel Spadoto-Dias

Departamento de Ginecologia e Obstetrícia, UNESP

Avenida Professor Mário Rubens Guimarães Montenegro, s/no

18.618-687 Botucatu - SP Brasil

Tels. (55 14)3880-1393 / 3880-1402

ddias.sp@fmb.unesp.br

Received: Sep 02, 2018

Review: Nov 06, 2018

Accepted: Dec 04, 2018
Conflict of interest: none

Financial source: none

\begin{abstract}
${ }^{1}$ Research performed at Clinics Hospital of Botucatu, Gynecological Endoscopy and Family Planning Sector, Department of Gynecology and Obstetrics, Botucatu Medical School, Universidade Estadual Paulista (UNESP), Botucatu-SP, Brazil.
\end{abstract}

